
\title{
Assessing the SMOS Soil Moisture Retrieval Parameters With High-Resolution NAFE'06 Data
}

\begin{abstract}
4 Abstract-The spatial and temporal invariance of Soil Moisture 5 and Ocean Salinity (SMOS) forward model parameters for soil 6 moisture retrieval was assessed at $1-\mathrm{km}$ resolution on a diurnal ba7 sis with data from the National Airborne Field Experiment 2006. 8 The approach used was to apply the SMOS default parameters 9 uniformly over $27 \mathbf{1 - k m}$ validation pixels, retrieve soil moisture 10 from the airborne observations, and then to interpret the differ11 ences between airborne and ground estimates in terms of land use, 12 parameter variability, and sensing depth. For pastures (17 pixels) 13 and nonirrigated crops ( 5 pixels), the root mean square error 14 (rmse) was $\mathbf{0 . 0 3}$ volumetric (vol./vol.) soil moisture with a bias of 150.004 vol./vol. For pixels dominated by irrigated crops (5 pixels), 16 the rmse was 0.10 vol./vol., and the bias was -0.09 vol./vol. 17 The correlation coefficient between bias in irrigated areas and 18 the $1-\mathbf{k m}$ field soil moisture variability was found to be $\mathbf{0 . 7 3}$, 19 which suggests either 1) an increase of the soil dielectric roughness 20 (up to about one) associated with small-scale heterogeneity of 21 soil moisture or/and 2) a difference in sensing depth between an 22 L-band radiometer and the in situ measurements, combined with 23 a strong vertical gradient of soil moisture in the top $6 \mathrm{~cm}$ of 24 the soil.
\end{abstract}

25 Index Terms-Airborne experiment, calibration, L-band ra26 diometry, National Airborne Field Experiment (NAFE), retrieval 27 algorithm, soil moisture, Soil Moisture and Ocean Salinity 28 (SMOS).

\section{INTRODUCTION}

$30 \Upsilon$ HE SOIL Moisture and Ocean Salinity (SMOS, [1]) 31 retrieval algorithm for soil moisture is based on an 32 L-band emission (forward) model calibrated for different soil 33 and vegetation classes [2], [3]. The main parameters involved 34 in the model are the near-surface soil moisture, soil texture, soil 35 surface roughness, soil effective temperature, and vegetation 36 optical depth. In the SMOS level 2 processor [4], brightness 37 temperature is simulated at a $1-4-\mathrm{km}$ resolution by the forward 38 model (land use and land cover are assumed to be uniform 39 at $1-4-\mathrm{km}$ resolution), aggregated to the SMOS observation 40 scale $(\sim 40 \mathrm{~km})$, and then compared with the SMOS observed 41 brightness temperature. The angular and polarization capa42 bilities of the SMOS antenna will allow retrieval of several 43 additional parameters (e.g., vegetation optical depth and soil

Manuscript received June 10, 2008; revised October 21, 2008 and December 4, 2008.

O. Merlin is with the Centre d'Etudes Spatiales de la Biosphère, 31401 Toulouse, France.

J. P. Walker and R. Panciera are with the Department of Civil and Environmental Engineering, The University of Melbourne, Melbourne, Vic. 3010, Australia.

M. J. Escorihuela is with IsardSAT, 08031 Barcelona, Spain.

T. J. Jackson is with the U.S. Department of Agriculture, Annapolis, MD 21409-5543 USA.

Digital Object Identifier 10.1109/LGRS.2008.2012727 roughness). However, the performance of multiparameter re- 44 trieval approaches [5] depends on how well the parameters 45 bounds are estimated, i.e., a priori knowledge of minimum and 46 maximum values. Retrieval assumes that the parameters are 47 rather stable at 1-4-km resolution. However, few experiments 48 have provided multiple angle and polarization L-band data at 49 the intermediate resolution of $\sim 1 \mathrm{~km}$ to verify this assumption. 50

One objective of the National Airborne Field Experiment 51 2006 (NAFE'06) was to map L-band brightness temperature 52 at 1-km resolution over a range of surface conditions includ- 53 ing grassland (pasture and fallow), dry land cropping (wheat, 54 barley, and oats) and irrigated cropping (wheat, alfalfa, canola, 55 rice, and corn) [6]. During NAFE'06, ground measurements of 56 the $0-6-\mathrm{cm}$ soil moisture were made coincident with $1-\mathrm{km}$ res- 57 olution flights on ten days during the three-week campaign that 58 included two rainfall events of about 7 and $13 \mathrm{~mm}$. NAFE'06 59 provided a unique data set to test the spatial invariance of 60 retrieval parameters over various land uses, vegetation covers, 61 and surface conditions at 1-km resolution. The approach used 62 was to apply SMOS default parameters uniformly over $271-\mathrm{km} 63$ validation pixels, retrieve surface soil moisture from the air- 64 borne observations, and then to interpret differences between 65 airborne and ground estimates in terms of land use, parameter 66 variability, and sensing depth.

\section{L-B AND EMISSION MODEL}

68

The SMOS forward model is based on the L-band Mi- 69 crowave Emission of the Biosphere model described in [2]. It 70 includes the tau-omega formulation [7] to express the polarized 71 $(\mathrm{H}$ or $\mathrm{V})$ brightness temperature as a function of incidence 72 angle, soil effective temperature, soil emissivity, and nadir op- 73 tical depth $(\tau)$ and single-scattering albedo $(\omega)$ of the canopy. 74 The soil microwave emissivity is calculated using the incidence 75 angle, the Fresnel equations, and the soil dielectric permittivity 76 that is computed using the Dobson model [8] and ancillary soil 77 texture. The soil roughness is accounted for using the approach 78 described in [9], which is based on two best fit parameters $H 79$ and $Q$. The nadir optical depth $\tau$ is related to vegetation water 80 content (VWC) by $\tau=b \times$ VWC [10] with $b$ a coefficient that 81 is generally obtained from field measurements. In this letter, 82 only the H-polarization (and H-polarized parameters) will be 83 considered.

Since the main objective of this letter is to assess the stability 85 of SMOS forward model parameters at a 1-km resolution, 86 the SMOS default parameters were used. The soil effective 87 temperature was computed based on the parameterization of 88 [11] using soil temperature in the $0-5-\mathrm{cm}$ soil layer, deep 89 soil temperature $(50 \mathrm{~cm})$, and the default parameter values 90 presented in [2]. The effects of temperature gradients within the 91 
TABLE I

Mean 1-km Field Variability of Ground Measurements and RMSE, Correlation Coefficient, Slope of the Linear

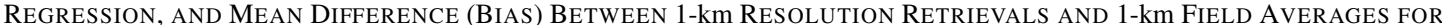
EACH OF THE 27 VALIDATION PIXELS. The Number of SAMPLing DaYs IS Also Listed

\begin{tabular}{|c|c|c|c|c|c|c|c|c|}
\hline $\begin{array}{l}\text { Pixel } \\
\text { label }\end{array}$ & $\begin{array}{c}\text { Main } \\
\text { land use }\end{array}$ & $\begin{array}{c}\text { Main } \\
\text { land cover }\end{array}$ & $\begin{array}{l}\text { Variability } \\
\text { (vol./vol.) }\end{array}$ & $\begin{array}{c}\text { RMSE } \\
\text { (vol./vol.) }\end{array}$ & $\begin{array}{l}\text { Correlation } \\
\text { coefficient }\end{array}$ & $\begin{array}{l}\text { Regression } \\
\text { slope }\end{array}$ & $\begin{array}{c}\text { Bias } \\
(\% \text { vol. })\end{array}$ & $\begin{array}{l}\text { Number } \\
\text { of days }\end{array}$ \\
\hline Y2a & grazing & grass & 0.026 & 0.035 & 0.87 & 0.87 & 0.007 & 10 \\
\hline $\mathrm{Y} 2 \mathrm{~b}$ & grazing & grass & 0.031 & 0.026 & 0.94 & 1.0 & 0.014 & 10 \\
\hline $\mathrm{Y} 2 \mathrm{c}$ & grazing & grass & 0.030 & 0.034 & 0.91 & 0.83 & 0.017 & 10 \\
\hline Y2d & grazing & grass & 0.035 & 0.042 & 0.83 & 1.1 & 0.005 & 10 \\
\hline $\mathrm{Y} 2 \mathrm{e}$ & grazing & grass & 0.036 & 0.043 & 0.79 & 0.78 & -0.008 & 10 \\
\hline Y2f & grazing & grass & 0.038 & 0.034 & 0.87 & 0.88 & 0.031 & 10 \\
\hline $\mathrm{Y} 2 \mathrm{~g}$ & grazing & grass & 0.041 & 0.034 & 0.92 & 1.2 & 0.008 & 10 \\
\hline $\mathrm{Y} 2 \mathrm{~h}$ & grazing & grass & 0.040 & 0.030 & 0.92 & 1.0 & 0.009 & 10 \\
\hline Y2i & grazing & grass & 0.042 & 0.023 & 0.94 & 0.89 & 0.004 & 10 \\
\hline Y9a & fallow & grass & 0.034 & 0.034 & 0.72 & 0.41 & 0.004 & 10 \\
\hline $\mathrm{Y9b}$ & fallow & grass & 0.025 & 0.024 & 0.90 & 0.74 & 0.012 & 9 \\
\hline Y9c & grazing & grass & 0.030 & 0.028 & 0.90 & 1.3 & -0.012 & 8 \\
\hline Y9d & cropping/grazing & alfalfa & 0.068 & 0.027 & 0.75 & 0.43 & 0.001 & 10 \\
\hline Y9e & cropping & oats/barley & 0.032 & 0.032 & 0.89 & 0.48 & 0.003 & 10 \\
\hline Y9f & grazing & grass & 0.044 & 0.026 & 0.84 & 0.75 & 0.003 & 10 \\
\hline Y9g & cropping* & alfalfa & 0.098 & 0.10 & 0.92 & 0.50 & -0.090 & 10 \\
\hline Y9h & cropping & grass & 0.059 & 0.042 & 0.85 & 0.58 & 0.022 & 10 \\
\hline Y9i & cropping & grass & 0.032 & 0.023 & 0.92 & 0.72 & -0.006 & 10 \\
\hline Y12a & cropping* & wheat & 0.033 & 0.056 & 0.85 & 0.52 & -0.044 & 8 \\
\hline Y12b & grazing & grass & 0.029 & 0.027 & 0.89 & 0.80 & -0.007 & 8 \\
\hline Y12c & grazing & grass & 0.027 & 0.037 & 0.81 & 0.95 & 0.007 & 8 \\
\hline Y12d & cropping* & wheat & 0.13 & 0.14 & 0.68 & 0.47 & -0.13 & 10 \\
\hline Y12e & cropping* & canola & 0.11 & 0.12 & 0.75 & 0.80 & -0.11 & 10 \\
\hline Y12f & grazing & grass & 0.035 & 0.043 & 0.78 & 0.87 & 0.005 & 10 \\
\hline Y12g & cropping* & cut corn & 0.090 & 0.089 & 0.86 & 0.93 & -0.086 & 9 \\
\hline Y12h & grazing & grass & 0.064 & 0.051 & 0.63 & 0.46 & -0.017 & 10 \\
\hline $\mathrm{Y} 12 \mathrm{i}$ & grazing & grass & 0.083 & 0.033 & 0.87 & 0.82 & -0.012 & 10 \\
\hline
\end{tabular}

92 canopy were assumed to be minimal by assuming the vegetation 93 temperature throughout the canopy is equal to the near-surface 94 soil temperature. The soil roughness parameter $H$ was set to 950.1 and the polarization-mixing parameter $Q$ to 0 [2]. The $b$ 96 parameter was set to a value 0.15 , which is representative of 97 most agricultural crops [10], and the single scattering albedo $\omega$ 98 to 0.05 [2]. Water interception in vegetation was assumed to be 99 negligible. Note that one pixel included $20 \%$ of rice under flood 100 irrigation. The contribution of standing water was removed 101 from the total emission by simulating the L-band emission over 102 water as a function of surface water temperature and incidence 103 angle [12].

\section{DATA}

105 NAFE'06 was undertaken during three weeks in Novem106 ber 2006 over a 40 by $60 \mathrm{~km}$ area in southeastern Australia $107\left(-34.9^{\circ} \mathrm{N} ; 146.1^{\circ} \mathrm{E}\right)$. In this letter, the study area is composed 108 of $271-\mathrm{km}$ resolution pixels included in three farms noted as 109 Y2, Y9, and Y12. Land use and land cover are listed in Table I. 110 Within each 1-km area, the 0-6-cm soil moisture was measured 111 on a 250-m resolution grid using a Hydraprobe. An average of 112 three successive measurements $\sim 1 \mathrm{~m}$ apart was made at each 113 node of the sampling grid, resulting in about 50 measurements 114 within each $1-\mathrm{km}$ pixel. Note that the calibration equation that 115 was applied to all measurements is site specific [13].
TABLE II

Mean and Standard Deviation of 0-6-cm Soil Moisture, H-POlarized BRIGHTNESS TEMPERATURE, AND NEAR-SURFACE SOIL TEMPERATURE FOR EACH OF THE TEN SAMPLING DAYS AT TIME OF AIRCRAFT OVERPASS. TWO RAINFALL EVENTS OCCURRED DURING THE THREE-WEEK CAMPAIGN WITH $\sim 7 \mathrm{~mm}$ ON JD 306-307 AND $\sim 13 \mathrm{~mm}$ ON JD 316-317

\begin{tabular}{cccc}
\hline & \multicolumn{3}{c}{$\begin{array}{c}\text { Mean (standard deviation) } \\
\text { brightness temperature }\end{array}$} \\
JD & $\begin{array}{c}\text { soil moisture } \\
\text { (vol./vol.) }\end{array}$ & $(\mathrm{K})$ & $\left({ }^{\circ} \mathrm{C}\right)$ \\
\hline 304 & $0.051(0.053)$ & $266(7.7)$ & $41(7.0)$ \\
306 & $0.057(0.058)$ & $269(7.7)$ & $36(2.4)$ \\
308 & $0.11(0.075)$ & $246(7.8)$ & $39(1.2)$ \\
309 & $0.085(0.063)$ & $259(8.8)$ & $39(1.3)$ \\
311 & $0.078(0.067)$ & $266(8.0)$ & $38(6.0)$ \\
313 & $0.059(0.056)$ & $267(8.1)$ & $39(1.4)$ \\
317 & $0.22(0.055)$ & $216(13)$ & $29(5.7)$ \\
318 & $0.18(0.047)$ & $240(9.5)$ & $31(4.8)$ \\
320 & $0.16(0.055)$ & $243(11)$ & $22(6.0)$ \\
322 & $0.098(0.040)$ & $263(9.9)$ & $44(1.1)$ \\
\hline
\end{tabular}

Concurrently with ground observations, the $\mathrm{H}-$ and 116 V-polarized brightness temperature was measured at 1-km res- 117 olution by the airborne Polarimetric L-band Multibeam Ra- 118 diometer (PLMR). Flights were undertaken in the window 119 8:00 A.M.-10:30 A.M. on Julian day (JD) 304, 306, 308, 120 

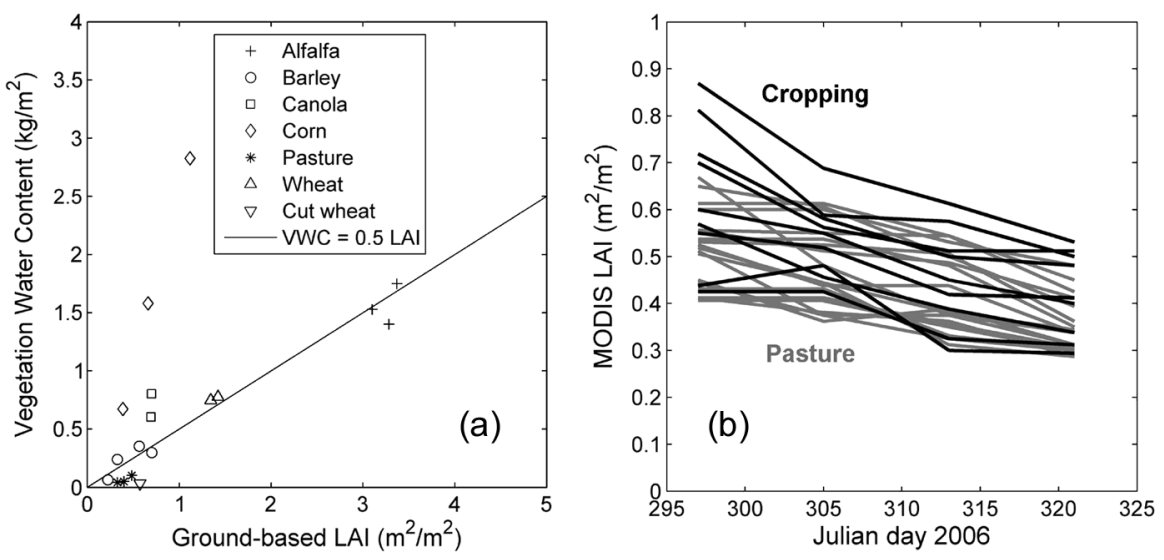

Fig. 1. (Left) Ground-based measurement of VWC versus LAI for each vegetation type in the study area, and (right) time series of MODIS eight-day LAI product extracted for each 1-km pixel.

$121309,311,313,320$, and 322 and in the window 11:00 A.M.122 1:30 P.M. on JD 317 and 318. The same flight lines were 123 kept across the campaign to obtain approximately the same 124 incidence angle over each pixel. Note that changes in aircraft 125 attitude were accounted for during processing by correcting the 126 zero tilt and roll incidence angle of the six beams (which are $127 \pm 7^{\circ}, \pm 21.5^{\circ}, \pm 38.5^{\circ}$ ) with respect to the topography. Details 128 about PLMR and its calibration can be found in [14]. Some 129 minor occurrences of sunglint were detected in the NAFE'06 130 area, but not over the sampling areas [15].

131 To compare ground and airborne observations, the point132 scale soil moisture measurements were averaged at $1-\mathrm{km}$ res133 olution within each of the 27 validation pixels. The along 134 track 1-km resolution radiometric measurements (together with 135 incidence angle) were also averaged within each $1-\mathrm{km}$ pixel. 136 Note that the mean number of PLMR acquisitions along a $1371-\mathrm{km}$ run was about 30 (with a time step of about $1.5 \mathrm{~s}$ and an 138 aircraft speed of $200 \mathrm{~km} / \mathrm{h}$ ). During the three-week experiment, 139 the mean soil moisture ranged from about 0.05 to 0.20 vol./vol. 140 corresponding to a mean brightness temperature of $270 \mathrm{~K}$ and 141220 K, respectively (see Table II).

142 VWC was estimated from MODIS/Terra 1-km resolution 143 eight-day LAI products on JD 297, 305, 313, and 312 using 144 the relationship VWC $=0.5$ LAI [16]. VWC maps were then 145 linearly interpolated between dates and regridded on the same $1461-\mathrm{km}$ grid as processed PLMR brightness temperature. The 147 relationship between VWC and LAI during NAFE'06 is shown 148 in Fig. 1(a) using ground observations obtained during the 149 campaign. The slope 0.5 appears to hold for all vegetation types 150 encountered except for corn, which has a slope of about three. 151 However, there was very little corn in the study area. The time 152 series of MODIS LAI for grazing and cropping pixels is shown 153 in Fig. 1(b). At 1-km resolution, LAI ranged from 0.4 to 0.8 154 and generally decreased by about 0.1 during the three-week 155 experiment.

156 To compute effective soil temperature, near-surface soil tem157 perature was estimated by the MODIS/Terra 1-km resolution 158 daily temperature on clear sky days (JD 304, 309, 311, 313, 159318,320 , and 322) and by the average of the 12 (six stations 160 distributed in the study area with two replicates per station) 161 simultaneous $-1-\mathrm{cm}$ soil temperature measurements on cloudy 162 days (JD 306, 308, and 317). Note that the mean ground soil 163 temperature was extracted for each pixel at the time of aircraft overflight (ranging from 8:30 A.M. to 12:30 A.M.). Table II 164 presents the time series of the mean and standard deviation of 165 near-surface soil temperature. Soil temperature at 50-cm depth 166 was also estimated from permanent monitoring stations in the 167 study region.

Soil texture was analyzed for 12 0-5-cm soil samples col- 169 lected in the study area. The mean and standard deviation of 170 sand and clay fractions were estimated as $0.26 \pm 0.10$ and 171 $0.27 \pm 0.11$, respectively. The highest measured sand fraction 172 was 0.59 (with a clay fraction of 0.11 ) and the highest clay 173 fraction was 0.49 (with a sand fraction of 0.11). In this letter, 174 the sand and clay fractions are assumed to be uniform and 175 set to 0.3 .

Soil surface roughness was measured with a pin profiler 177 at five locations within each farm. As the link between the 178 measured geometrical roughness and $H$ parameter is not well 179 known [2], those measurements were not used in this letter. $\quad 180$

\section{RETRIEVAL RESUlTS}

Airborne soil moisture was retrieved by minimizing a cost 182 function. This cost function is defined as the root mean square 183 difference between the $\mathrm{H}$-polarized brightness temperature 184 modeled by the radiative transfer model and that observed by 185 the aircraft. All parameters were uniformly set to the values 186 presented above, i.e., soil moisture was the only free parameter 187 in the minimization. The V-polarized brightness temperature 188 was not included in the cost function to simplify the interpreta- 189 tion of retrieval results due to the uncertainty of polarization 190 dependence on the parameters (e.g., roughness). Note that 191 the retrieval was done at the $1-\mathrm{km}$ resolution and the effects 192 of mixed surface in the $1-\mathrm{km}$ resolution footprint were not 193 accounted for except in the presence of standing water.

Fig. 2 compares the 1-km field soil moisture average (cross) 195 and variability (whisker) with the soil moisture retrieval for 196 farms Y2, Y9, and Y12. The 1-km field variability of soil 197 moisture was computed as the standard deviation of the ground 198 measurements within the 1-km PLMR pixel. In most cases, 199 the difference between ground measurements and airborne 200 estimates was smaller than the 1-km field variability (see 201 Table I). However, a significant bias was apparent for the five 202 irrigated pixels (labeled Y9g, Y12a,d,e,g), although only one 203 pixel (Y9g) contained a measurable fraction $(20 \%)$ of standing 204 water. Table I lists for each of the 27 validation pixels the root 205 


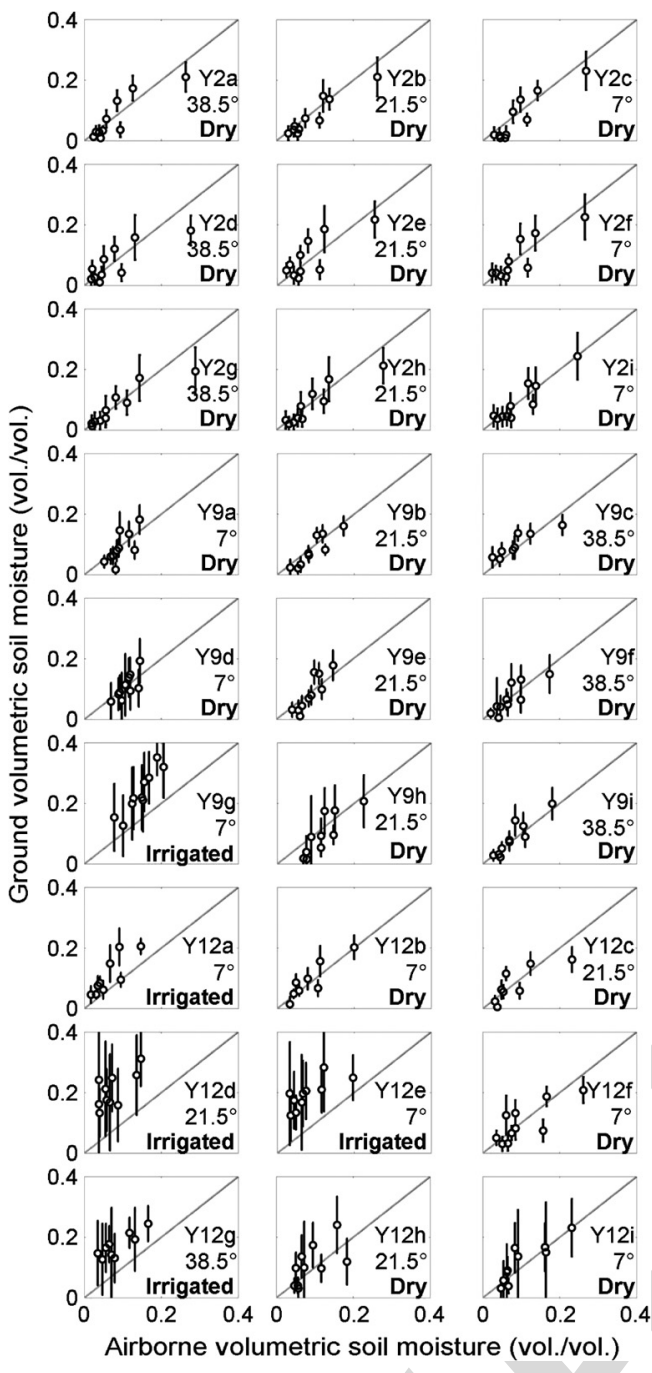

Fig. 2. One-kilometer (cross) field average and (whisker) variability of in situ measurements versus retrievals at the $271-\mathrm{km}$ resolution validation pixels. Pixel label and mean incidence angle are also indicated.

206 mean square error (rmse), the correlation coefficient, and the 207 bias between airborne retrievals and ground measurements. For 208 the 22 nonirrigated pixels, the rmse is $0.033( \pm 0.009)$ vol./vol. 209 with a correlation coefficient of $0.85( \pm 0.07)$ and a bias of 0.004 $210( \pm 0.010)$ vol./vol. when using the SMOS default parameters. 211 For the five irrigated pixels, the rmse is $0.10( \pm 0.032)$ vol./vol. 212 with a correlation coefficient of $0.81( \pm 0.10)$ and a bias of $213-0.093( \pm 0.034)$ vol./vol.

214 The bias observed for the airborne soil moisture estimates in 215 the five irrigated pixels could be explained by several factors: 216 The spatial variability of soil texture, soil roughness and/or 217 vegetation. First, soil texture (i.e., sand and clay fractions) 218 impacts the modeled soil emissivity, which in turn impacts the 219 retrieved soil moisture. However, when using the parameters 220 of the soil with the highest measured sand fraction and then 221 those with the highest measured clay fraction in the retrieval 222 algorithm (results not shown), the root mean square difference 223 between the two output data sets was only 0.027 vol./vol., 224 which is much smaller than the observed bias ( 0.09 vol./vol.).

225 Soil geometric roughness impacts the slope of the relation226 ship between soil moisture retrievals and ground measurements. 227 In order to assess the variability of soil geometric roughness at 1-km resolution, we examined the slope of the linear regression 228 between airborne and ground estimates (Table I). The slope 229 is $0.87 \pm 0.21$ for grazing pixels, $0.56 \pm 0.13$ for dry land 230 cropping pixels, and $0.65 \pm 0.20$ for irrigated cropping pixels. 231 The difference in the slopes between the grazing and cropping 232 classes was associated with an increase in roughness with 233 agricultural practices in cropped fields (e.g., plowing, irrigation 234 rows, etc.). However, no significant difference in the slopes 235 was observed between the irrigated and nonirrigated areas. 236 Consequently, soil geometric roughness is not considered to be 237 the main cause of the bias observed in the irrigated pixels. 238

The last factor considered was vegetation. The different 239 effects (attenuation, scattering and emission) of vegetation at L- 240 band generally result in an increase of the surface emission. An 241 increase of vegetation optical depth would thus make the soil 242 moisture retrieval lower. However, vegetation cannot explain a 243 0.09 vol./vol. decrease in retrieved soil moisture because vege- 244 tation cover was relatively low at $1-\mathrm{km}$ resolution (LAI ranged 245 from 0.4 to 0.8 ). Moreover, the $b$ parameter was fixed in the 246 higher range for crops $(0.05-0.20)$, which already maximizes 247 the vegetation impact on the modeled brightness temperature. 248 As an illustration, the irrigated canola in Y12e was harvested 249 during the middle of the campaign, but harvesting did not 250 remove the bias on retrievals (see Fig. 2).

If none of the parameters of the L-band emission model 252 can provide an obvious explanation of the bias found for the 253 airborne estimates, then one may argue that perhaps the ground 254 sensor calibration is not valid in irrigated areas. Four out of the 255 five irrigated pixels are located in the most clayey farm Y12, 256 and it is known that clay fraction can potentially increase the 257 ground sensor response [13]. However, soil type was similar 258 at the farm scale, and no significant bias was observed for the 259 five nonirrigated pixels of Y12 (see Fig. 2). Consequently, the 260 calibration of the ground sensor, which mainly depends on soil 261 type, is considered to be reliable for irrigated areas as well. 262

Having considered the uncertainty in retrieval model inputs 263 and ground measurement data, it was concluded that the poor 264 retrieval results in irrigated areas was due to either a difference 265 in sensing depth between ground and airborne measurements 266 and/or an error in the modeling of soil roughness. The first 267 hypothesis was to consider the different depths of soil involved 268 in the direct and remote measurements. During or immediately 269 after irrigation, the soil moisture of the first layer sensed by 270 the L-band radiometer $(0-3 \mathrm{~cm}$ according to [17]) could be 271 different to the soil moisture of the lower layer $(3-6 \mathrm{~cm})$ that 272 instead affects the soil moisture measurements carried out by 273 using 0-6-cm Hydraprobes. This hypothesis is supported by 274 the relatively high correlation (estimated to 0.73 ) between the 275 bias on retrievals and the $1-\mathrm{km}$ field soil moisture variability 276 [see Fig. 3(a)]. However, no information on the soil moisture 277 profile in the top $6 \mathrm{~cm}$ was available to confirm the link between 278 vertical and horizontal variability. The second hypothesis was 279 to consider an increase of the "dielectric roughness" with the 280 variability of moisture within the soil. To illustrate the possible 281 impact of the soil moisture variability on soil dielectric rough- 282 ness, parameter $H$ was retrieved in the four irrigated pixels of 283 Y12 by setting soil moisture to ground measurements. Fig. 3(b) 284 shows that the retrieved effective roughness does increase (up 285 to about one) as a function of the $1-\mathrm{km}$ field soil moisture 286 variability with a correlation coefficient estimated to 0.67 . 

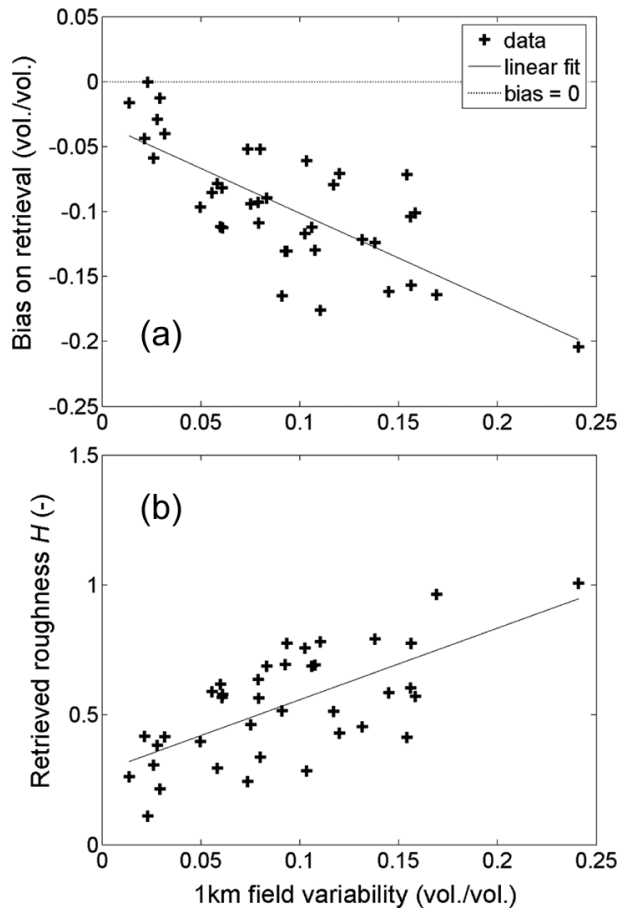

Fig. 3. Difference between (a) airborne and ground estimates and (b) retrieved soil roughness parameter $H$ versus 1 -km field soil moisture variability including data from the four irrigated pixels in Y12.

\section{CONCLUSION}

289 The temporal and spatial invariance of the SMOS forward 290 model parameters was assessed at a $1-\mathrm{km}$ resolution on a 291 diurnal basis using the NAFE'06 data. The approach used 292 was to apply the SMOS default parameters uniformly over 27 293 1-km pixels, retrieve soil moisture from the airborne observa294 tions, and then to interpret differences between airborne and 295 ground estimates in terms of land use, parameter variability, and 296 sensing depth. For nonirrigated (grazing and cropping) areas, 297 the rmse on retrievals was 0.03 vol./vol. and the correlation 298 coefficient with ground measurements was 0.85 . The impact 299 of soil geometric roughness was noted by correlating the slope 300 of the linear regression between airborne and ground estimates 301 with agricultural practices. A roughness parameter $H=0.1$ 302 was found to be appropriate for grazing areas (slope was 303 about one), while a slightly higher roughness was identified 304 for cropping areas (slope was about 0.7). A significant mean 305 difference of -0.09 vol./vol. between airborne and ground 306 estimates was observed in the five irrigated pixels. As no 307 parameter (soil texture, soil geometric roughness, vegetation) 308 could explain this bias, it is suggested that either a strong 309 vertical gradient of near-surface soil moisture in irrigated areas 310 made the $0-6-\mathrm{cm}$ ground measurements generally wetter than 311 the $0-3-\mathrm{cm}$ retrievals and/or the small-scale variability of soil 312 moisture made the effective soil roughness increase up to 313 about one.

\section{ACKNOWLEDGMENT}

315 The authors would like to thank the NAFE'06 participants. 316 The NAFEs have been made possible through recent infrastruc317 ture (LE0453434 and LE0560930) and research (DP0557543) 318 funding from the Australian Research Council, and the col- laboration of a large number of scientists from throughout 319 Australia, U.S., and Europe. Initial setup and maintenance 320 of the study catchments was funded by a research Grant 321 (DP0343778) from the Australian Research Council and by the 322 Cooperative Research Centre for Catchment Hydrology. 323

\section{REFERENCES}

[1] Y. H. Kerr, P. Waldteufel, J.-P. Wigneron, J.-M. Martinuzzi, J. Font, and 325 M. Berger, "Soil moisture retrieval from space: The soil moisture and 326 ocean salinity (SMOS) mission," IEEE Trans. Geosci. Remote Sens., 327 vol. 39, no. 8, pp. 1729-1735, Aug. 2001.

328

[2] J.-P. Wigneron, Y. Kerr, P. Waldteufel, K. Saleh, M.-J. Escorihuela, 329 P. Richaume, P. Ferrazzoli, P. de Rosnay, R. Gurneye, J.-C. Calvet, 330 J. P. Grant, M. Guglielmettih, B. Hornbuckle, C. Matzler, T. Pellarin, 331 and M. Schwank, "L-band microwave emission of the biosphere (L- 332 MEB) Model: Description and calibration against experimental data sets 333 over crop fields," Remote Sens. Environ., vol. 107, no. 4, pp. 639-655, 334 Apr. 2007.

[3] K. Saleh, J.-P. Wigneron, P. Waldteufel, P. de Rosnay, M. Schwank, 336 J.-C. Calvet, and Y. H. Kerr, "Estimates of surface soil moisture under 337 grass covers using L-band radiometry," Remote Sens. Environ., vol. 109, 338 no. 1, pp. 42-53, Jul. 2007.

339

[4] Y. H. Kerr, P. Waldteufel, P. Richaume, I. Davenport, P. Ferrazzoli, and 340 J.-P. Wigneron, SMOS Level 2 Processor Soil Moisture Algorithm Theo- 341 retical Basis Document (ATBD). Toulouse, France: CESBIO, 2006. SM- 342 ESL (CBSA), vol. SO-TN-ESL-SM-GS-0001, V5.a..

343

[5] M. Parde, J.-P. Wigneron, P. Waldteufel, Y. H. Kerr, A. Chanzy, 344 S. S. Sobjaerg, and N. Skou, "N-parameter retrievals from L-band mi- 345 crowave observations acquired over a variety of crop fields," IEEE Trans. 346 Geosci. Remote Sens., vol. 42, no. 6, pp. 1168-1178, Jun. 2004.

[6] O. Merlin, J. P. Walker, J. D. Kalma, E. J. Kim, J. Hacker, R. Panciera, 348 R. Young, G. Summerell, J. Hornbuckle, M. Hafeez, and T. J. Jackson, 349 "The NAFE'06 data set: Towards soil moisture retrieval at intermedi- 350 ate resolution," Adv. Water Resour, vol. 31, no. 11, pp. 1444-1455, 351 Nov. 2008. DOI: 10.1016/j.advwatres.2008.01.018..

[7] T. Mo, B. J. Choudhury, T. J. Schmugge, J. R. Wang, and T. J. Jackson, 353 "A model for microwave emission from vegetation-covered fields," J. 354 Geophys. Res., vol. 87, no. 13, pp. 11 229-11 237, 1982.

[8] M. C. Dobson, F. T. Ulaby, M. T. Hallikainen, and M. A. El-Reyes, 356 "Microwave dielectric behavior of wet soil-Part II: Dielectric mixing 357 models," IEEE Trans. Geosci. Remote Sens., vol. GRS-23, no. 1, pp. 35- 358 46, Jan. 1985.

359

[9] J. R. Wang and B. J. Choudhury, "Remote sensing of soil moisture content 360 over bare field at $1.4 \mathrm{GHz}$ frequency," J. Geophys. Res., vol. 86, no. C6, 361 pp. 5277-5282, Jun. 1981.

[10] T. J. Jackson and T. J. Schmugge, "Vegetation effects on the microwave 363 emission of soils," Remote Sens. Environ., vol. 36, no. 3, pp. 203-212, 364 Jun. 1991.

[11] B. Choudhury, T. Schmugge, and T. Mo, "A parametrization of effective 366 soil temperature for microwave emission," J. Geophys. Res., vol. 87, 367 no. C2, pp. 1301-1304, 1982.

368

[12] F. T. Ulaby, R. K. Moore, and A. K. Fung, Microwave Remote Sensing: 369 Active and Passive, vol. 1. Norwood, MA: Artech House, 1981. 370

[13] O. Merlin, J. Walker, R. Panciera, R. Young, J. Kalma, and E. Kim, "Soil 371 moisture measurement in heterogeneous terrain," in Proc. Int. Congr. 372 Model. Simul. MODSIM - Modelling and Simulation Society of Australia 373 and New Zealand, New Zealand, Dec. 2007, pp. 2604-2610.

374

[14] R. Panciera, J. P. Walker, J. D. Kalma, E. J. Kim, J. Hacker, 375 O. Merlin, M. Berger, and N. Skou, "The NAFE'05/CoSMOS data set: 376 Toward SMOS calibration, downscaling and assimilation," IEEE Trans. 377 Geosci. Remote Sens., vol. 46, no. 3, pp. 736-745, Mar. 2008. DOI: 378 10.1109/TGRS.2007.915403..

379

[15] M. J. Escorihuela, K. Saleh, P. Richaume, O. Merlin, J. P. Walker, and 380 Y. Kerr, "Sunglint observations over land from ground and airborne L- 381 band radiometer data," Geophys. Res. Lett., vol. 35, no. 20, p. L20 406, 382 Oct. 2008. DOI: 10.1029/2008GL035062.

[16] J.-P. Wigneron, A. Chanzy, J.-C. Calvet, A. Olioso, and Y. Kerr, "Mod- 384 eling approaches to assimilating L-band passive microwave observations 385 over land surfaces," J. Geophys. Res., vol. 107, no. D14, pp. ACL 11.1- 386 ACL 11.14, Jul. 2002. doi:10.1029/2001JD000958.

[17] S. Raju, A. Chanzy, J.-P. Wigneron, J.-C. Calvet, Y. Kerr, and L. Laguerre, 388 "Soil moisture and temperature profile effects on microwave emission 389 at low frequencies," Remote Sens. Environ., vol. 54, no. 2, pp. 85-97, 390 Nov. 2005. 


\section{AUTHOR QUERIES}

\section{AUTHOR PLEASE ANSWER ALL QUERIES}

ATTN: If you are paying to have all or some of your figures appear in color in the print issue, it is very important that you fill out and submit a copy of the IEEE Page Charge \& Reprint Form along with your proof corrections. This form is available from the same URL where these page proofs were downloaded from. Thank you.

END OF ALL QUERIES 